\title{
Empowering family physicians to impart proper inhaler teaching to patients with chronic obstructive pulmonary disease and asthma
}

\author{
Janice M Leung MD ${ }^{1}$, Mohit Bhutani MD², Richard Leigh MD $\mathrm{PhD}^{3}$, Dan Pelletier $\mathrm{BA}^{4}$, \\ Cathy Good RN ${ }^{5}$, Don D Sin MD MPH ${ }^{1,6}$
}

JM Leung, M Bhutani, R Leigh, D Pelletier, C Good, DD Sin. Empowering family physicians to impart proper inhaler teaching to patients with chronic obstructive pulmonary disease and asthma. Can Respir J 2015;22(5):266-270.

BACKGROUND: Patients with chronic obstructive pulmonary disease (COPD) and asthma depend on inhalers for management, but critical errors committed during inhaler use can limit drug effectiveness. Outpatient education in inhaler technique remains inconsistent due to limited resources and inadequate provider knowledge.

OBJECTIVE: To determine whether a simple, two-session inhaler education program can improve physician attitudes toward inhaler teaching in primary care practice.

METHODS: An inhaler education program with small-group hands-on device training was instituted for family physicians (FP) in British Columbia and Alberta. Sessions were spaced one to three months apart. All critical errors were corrected in the first session. Questionnaires surveying current inhaler teaching practices and attitudes toward inhaler teaching were distributed to physicians before and after the program.

RESULTS: Forty-one (60\%) of a total 68 participating FPs completed both before and after program questionnaires. Before the program, only 20 (49\%) reported providing some form of inhaler teaching in their practices, and only four $(10 \%)$ felt fully competent to teach patients inhaler technique. After the program, 40 (98\%) rated their inhaler teaching as good to excellent. Thirty-four $(83 \%)$ reported providing inhaler teaching in their practices, either by themselves or by an allied health care professional they had personally trained. All stated they could teach inhaler technique within $5 \mathrm{~min}$. Observation of FPs during the second session by certified respiratory educators found that none made critical errors and all had excellent technique.

CONCLUSION: A physician inhaler education program can improve attitudes toward inhaler teaching and facilitate implementation in clinical practices.

Key Words: Asthma; COPD; Inhaler devices; Medical education; Primary care

\begin{abstract}
Apprendre aux médecins de famille à bien enseigner l'utilisation de l'inhalateur aux patients atteints d'une maladie pulmonaire obstructive chronique ou d'asthme
\end{abstract}

HISTORIQUE : Les patients atteints d'une maladie pulmonaire obstructive chronique (MPOC) ou d'asthme dépendent des inhalateurs pour se soigner, mais des erreurs déterminantes d'utilisation peuvent limiter l'efficacité du médicament. L'apprentissage de la technique d'utilisation de l'inhalateur en milieu ambulatoire demeure hétérogène en raison du peu de ressources et des connaissances limitées des dispensateurs.

OBJECTIF : Déterminer si un programme d'apprentissage simple d'utilisation des inhalateurs en deux séances peut améliorer les attitudes des médecins envers l'enseignement de la technique d'inhalation en première ligne.

MÉTHODOLOGIE : Un programme d'apprentissage pour utiliser l'inhalateur dans le cadre d'une formation pratique en petits groupes a été créé pour les médecins de famille (MF) de la Colombie-Britannique et de l'Alberta. Les séances étaient espacées de un à trois mois. Toutes les erreurs déterminantes ont été corrigées pendant la première séance. Les médecins ont reçu des questionnaires sondant leurs pratiques et leurs attitudes d'enseignement avant et après le programme.

RÉSULTATS : Quarante et un des $68 \mathrm{MF}$ participants (60\%) ont rempli le sondage avant et après le programme. Avant le programme, seulement 20 (49\%) donnaient une forme d'enseignement dans leur pratique, et seulement quatre $(10 \%)$ se sentaient pleinement compétents à le faire. Après le programme, 40 (98\%) ont évalué leur enseignement comme bon à excellent. Trentequatre $(83 \%)$ ont indiqué donner ce type d'enseignement dans leur pratique, soit eux-mêmes, soit par l'entremise d'un autre professionnel de la santé qu'ils avaient personnellement formés. Tous déclaraient pouvoir enseigner la technique d'utilisation de l'inhalateur en cinq minutes. Des inhalothérapeutes ont observé les MF pendant la deuxième séance et attesté qu'aucun ne faisait d'erreur déterminante et que tous possédaient une excellente technique. CONCLUSION : Un programme d'apprentissage de la technique d'utilisation des inhalateurs par les médecins peut améliorer les attitudes envers l'enseignement de la technique et en faciliter l'adoption en milieu clinique.

those COPD and asthma patients found to commit at least one critical error when using their inhaler devices (7). Moreover, improper use can lead to significant oropharyngeal rather than pulmonary deposition of drug, thereby increasing the chances that patients will suffer side effects with reduced clinical benefit.

Educating patients regarding proper inhaler use has been shown to not only improve their technique, but also their clinical outcomes (8-10). Implementation of inhaler education into clinical practices is challenging. Few physicians and allied health care professionals provide inhaler education on a regular basis, with time constraints cited as a major reason $(11,12)$. More disconcerting is the fact that health care providers themselves often exhibit poor technique when (4-6). The consequences of improper inhaler technique can be profound. The use of systemic steroids and antibiotics, not to mention rates of hospitalization and emergency room visits, is increased in

${ }^{1}$ Centre for Heart Lung Innovation, St Paul's Hospital, University of British Columbia, Vancouver, British Columbia; ${ }^{2}$ Division of Pulmonary Medicine, University of Alberta, Edmonton; ${ }^{3}$ Division of Respiratory Medicine, University of Calgary, Calgary, Alberta; ${ }^{4}$ AstraZeneca Canada Inc, Mississauga, Ontario; ${ }^{5}$ GoodInnovations, Calgary, Alberta; ${ }^{6}$ Division of Respiratory Medicine, St Paul's Hospital, University of British Columbia, Vancouver, British Columbia

Correspondence: Dr Don D Sin, St Paul's Hospital, University of British Columbia, Room 166-1081 Burrard Street, Vancouver,

British Columbia V6Z 1Y6. Telephone 604-806-8346, e-mail don.sin@hli.ubc.ca 
asked to demonstrate inhaler device use $(12,13)$, raising questions as to their ability to teach patients even if they had the time to do it. In the present study, we implemented a two-session education program for family physicians with small-group hands-on inhaler device teaching aimed at improving patient inhaler use. Physician attitudes before and after the program were assessed via questionnaire surveys to determine the impact of the program on comfort with and implementation of inhaler device teaching in clinical practices.

\section{METHODS}

Inhaler education program

An inhaler education program targeted at family physicians (FPs) was instituted at three different Canadian locations (Vancouver [British Columbia], and Calgary and Edmonton [Alberta]) between April 2013 and June 2014. Physicians enrolled in the Vancouver program were drawn from around British Columbia, while physicians enrolled in the Calgary and Edmonton programs were drawn locally. The program consisted of two separate sessions spaced one to three months apart (depending on participating physician availability) with the aim of providing didactic repetition (14). The first session provided didactic teaching in the principles of drug particle delivery to the lungs as well as hands-on technical teaching for metered dose inhalers (MDIs) (with and without spacer devices) and dry powder inhalers (DPIs) (Turbuhaler, AstraZeneca Canada Inc; Diskus, GlaxoSmithKline Inc, Canada; Handihaler, Boehringer Ingelheim, USA; Twisthaler, Merck Canada Inc; and Breezhaler, Novartis Pharmaceuticals Canada Inc) by certified respiratory educators (CREs). Checklists of step-by-step instructions for proper MDI and DPI use, distributed by the Canadian Lung Association, were employed to ensure adequate performance (these are provided in the Supplemental Figure S1 [go to www.pulsus. com]). FPs were then instructed to apply these lessons to their practice in the interim between the first and second sessions. The second session reviewed the principles of the first session with reiteration of the hands-on inhaler technique teaching and their techniques were observed and rated by CREs. Slide decks and access to placebo inhalers were also provided to the physicians with the aim for physicians to not only teach patients proper inhaler technique, but also to disseminate these lessons among other physicians and allied health care professionals in their primary care practices and their communities.

\section{Physician questionnaires}

Before the first session, FPs enrolled in the program were asked to complete a questionnaire regarding their current practice habits on inhaler teaching. This survey is reproduced in its original form in Appendix 1. Three to six months after the end of the second session, physicians were then contacted again to complete a second electronic questionnaire (SurveyMonkey, USA) regarding the impact of the program on their inhaler teaching practices. This second survey is reproduced in its original form in Appendix 2. Physicians were allowed to remain anonymous when completing both questionnaires.

\section{Statistics}

The program coordinator collated results from the two questionnaires. Summary descriptive statistics were performed in Excel (Microsoft Corporation, USA) and in JMP version 10.0.2 (SAS Institute, USA).

Ethics and informed consent

Participating physicians were notified of the use of their answers for research purposes and consented to this provision before completion of the questionnaires.

\section{RESULTS}

Participant demographics

Characteristics of participating physicians are summarized in Table 1. Of a total of 68 participating physicians ( 23 from British Columbia, 25 from Edmonton and 20 from Calgary), 41 (60\%) completed both preand post-education session surveys (18 [44\%] from British Columbia,
TABLE 1

Pre-education session evaluation

\begin{tabular}{|c|c|}
\hline Question & $\begin{array}{c}\text { Response, } \\
n=41\end{array}$ \\
\hline \multicolumn{2}{|l|}{ Years in practice* } \\
\hline $1-5$ & $1(2.5)$ \\
\hline $5-10$ & $3(7.5)$ \\
\hline $10-15$ & $5(12.5)$ \\
\hline$>15$ & $31(77.5)$ \\
\hline \multicolumn{2}{|l|}{ Location } \\
\hline British Columbia & $18(43.9)$ \\
\hline Edmonton, Alberta & $17(41.5)$ \\
\hline Calgary, Alberta & $6(14.6)$ \\
\hline \multicolumn{2}{|l|}{ Number of asthma/COPD patients per week ${ }^{\dagger}$} \\
\hline $1-10$ & $5(12.8)$ \\
\hline 10-20 & $23(59.0)$ \\
\hline$>20$ & $11(28.2)$ \\
\hline Received prior hands-on education in inhaler use & $24(58.5)$ \\
\hline Provides inhaler education to patients $\ddagger$ & $20(48.8)$ \\
\hline Metered dose inhalers, $n / n$ & $14 / 20$ \\
\hline Dry powder inhalers, $\mathrm{n} / \mathrm{n}$ & $19 / 20$ \\
\hline Spacer devices, $\mathrm{n} / \mathrm{n}$ & $13 / 20$ \\
\hline Inhaler care, $\mathrm{n} / \mathrm{n}$ & $7 / 20$ \\
\hline Does not provide inhaler education $\ddagger$ & $21(51.2)$ \\
\hline Too busy, $\mathrm{n} / \mathrm{n}$ & $10 / 21$ \\
\hline Pharmacist, nurse or RT will take care of this, $n / n$ & $18 / 21$ \\
\hline Patients are typically good at using devices, $n / n$ & $1 / 21$ \\
\hline \multicolumn{2}{|l|}{ Perceived competency in inhaler teaching ${ }^{\ddagger}$} \\
\hline Fully competent & $4(9.8)$ \\
\hline Somewhat competent & $35(85.4)$ \\
\hline Not competent & $4(9.8)$ \\
\hline
\end{tabular}

Data presented as $n$ (\%) unless otherwise indicated. *2 missing data points; †3 missing data points; ${ }^{\ddagger 1}$ missing data point. COPD Chronic obstructive pulmonary disease; RT Respiratory technician

17 [41\%] from Edmonton and six [15\%] from Calgary). Results are reported for these 41 physicians. The majority of physicians (77\%) had practiced for $>15$ years. Five (13\%) reported seeing between one and 10 asthma or COPD patients per week, 23 (59\%) between 10 and 20, and $11(28 \%)>20$. Only $24(59 \%)$ physicians had ever received prior hands-on education in how to use inhalers (of those who further described where this education was provided, eight reported receiving this education during medical school, one from a pharmaceutical company representative and six through continuing medical education programs). At the first session, all of the participating FPs made critical errors in the use of inhalers (eg, unable to open cap and poor breath holding), as noted by the CREs conducting the small group hands-on training sessions. However, all of these errors were remedied during this session. At the second face-to-face session, CREs observed each of the participating physician's ability to use the inhaler devices and rated their performance as excellent.

\section{Pre-education session self-assessment of inhaler teaching}

Before the inhaler education sessions, participating physicians were asked to evaluate the inhaler teaching currently provided to patients in their practices. These results are also shown in Table 1. Only 20 (49\%) reported providing inhaler education to patients. Of these 20, 14 reported providing teaching on MDIs, 19 on DPIs and 13 on spacer devices. Only nine reported providing teaching on all three types of devices and seven reported teaching patients on inhaler care, including how to determine whether an inhaler is empty. For the 21 (51\%) physicians who provided no inhaler teaching as part of their medical practice, 10 cited that they were too busy to provide this service and 14 believed that pharmacists were providing this teaching instead. 


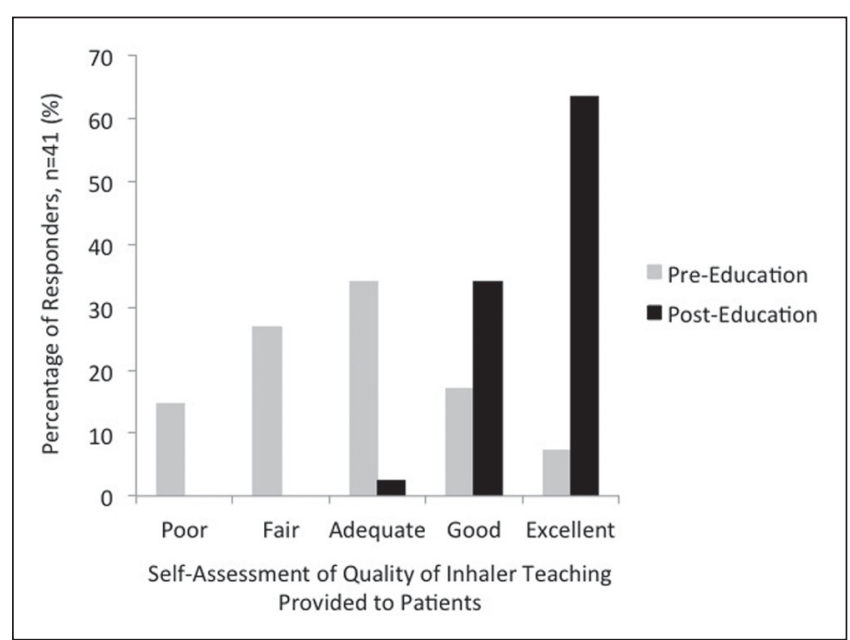

Figure 1) The quality of inhaler teaching provided to patients as selfassessed by physicians before (grey bars) and after (black bars) the inhaler education program. The percentage of responders reporting good to excellent quality of inhaler teaching increased following completion of the inhaler education program

One physician reported that patients were already competent at using inhaler devices. Overall, only four (10\%) physicians felt fully competent at provider inhaler teaching for their patients. Thirty-five (85\%) felt somewhat competent and four (10\%) did not feel they were at all competent to teach patients on inhaler use.

\section{Post-education session self-assessment of inhaler device teaching}

Following completion of the inhaler device education program, FPs were asked to assess the change in the quality of their inhaler teaching to patients. Only $10(24 \%)$ rated the quality of their inhaler device teaching before the program as either good or excellent. Six (15\%) rated the quality of their inhaler device teaching as poor. After the program, however, the percentage of responders reporting good to excellent quality of inhaler teaching increased. Forty (98\%) now rated their inhaler teaching as either good or excellent with no physicians reporting poor or fair quality teaching (Figure 1). Twenty-five (61\%) reported now doing the majority of device teaching in their practices with another nine $(22 \%)$ having trained support staff or other allied health care practitioners within their practices to provide inhaler teaching. Twenty-one (51\%) stated that teaching inhaler device technique required $3 \mathrm{~min}$ to $5 \mathrm{~min}$ of a clinic visit, while 19 (46\%) reported they could provide this teaching in $\leq 2 \mathrm{~min}$. The most commonly reported subjective physician free-text comments on the inhaler education program are reported in Table 2. Twenty-two (54\%) FPs reported witnessing improved efficacy of inhaler medications in their patients. Ten (24\%) reported witnessing improved patient adherence and motivation, and 11 (27\%) felt personal satisfaction that they were providing improved care as a primary care physician.

\section{DISCUSSION}

For COPD and asthma, airways diseases for which no curative therapies currently exist, inhaler medications represent the mainstay of pharmacological treatment. Their complexity in design in terms of delivering medication to the airways, however, render inhaler devices dependent on patients employing proper technique for the drugs to work. Efforts to improve patient proficiency with inhalers are sadly lacking in primary care clinical practice. In the present study, we demonstrate that a physician education program specifically addressing pulmonary drug delivery principles (to elucidate why technique is important) and the practical aspects of inhaler use can alter the attitudes of FPs toward inhaler teaching and can facilitate its implementation in the outpatient primary care setting. Notably, physicians who had previously considered their knowledge on inhalers deficient now felt confident to report they
TABLE 2

Post-education session - perceived outcome statements*

\begin{tabular}{lc}
\hline Outcome & $\begin{array}{c}\text { Response, } \\
\mathbf{n = 4 1}\end{array}$ \\
\hline Perceived improvement in efficacy of drugs & $22(53.7)$ \\
Perceived improvement in patient compliance and motivation & $10(24.4)$ \\
Increased physician satisfaction in improving patient care & $11(26.8)$ \\
Improved patient satisfaction and knowledge & $9(21.4)$ \\
Increased physician confidence & $7(16.7)$ \\
Perceived minimized side effects & $5(11.9)$ \\
\hline
\end{tabular}

$\overline{\text { Data presented as } n(\%) .{ }^{*} \text { Free text comments were captured and categorized }}$ according to topic

were providing good to excellent inhaler teaching to their patients. As a result, more FPs were incorporating inhaler teaching into their practices, whether providing this service themselves or training other members of their staff to perform this teaching.

Importantly, the addition of inhaler teaching was not considered to be particularly burdensome from a time standpoint, because all participating FPs reported being able to teach inhaler technique in $<5 \mathrm{~min}$. Whether this allotted time is sufficient for adequate impartment of knowledge would be grounds for further study, as a previous report in the literature suggests that patients who were provided teaching in the $6 \mathrm{~min}$ to $10 \mathrm{~min}$ range made fewer errors than those whose teaching lasted between $1 \mathrm{~min}$ to $5 \mathrm{~min}$ (15). Key elements of our education program include direct observation of inhaler device technique by CREs and a multiple session format that takes advantage of learning repetition interspersed by practical application. The latter in particular has been shown to improve both short- and long-term retention in medical education (14). The use of a simple, step-by-step inhaler technique guide also enhanced our education program, because past investigations have found that patients do not always adequately learn proper inhaler technique simply from manufacturer instruction leaflets alone $(16,17)$.

The findings of our study support the belief that inhaler device education in current primary care clinical practices is poorly implemented, either due to time or knowledge. Before our program, fewer than one-half of surveyed FPs reported providing some form of inhaler education to their patients, even fewer providing this service on the extensive range of devices now available for COPD and asthma patients (MDIs, DPIs and spacer devices). Surveys of COPD and asthma patients worldwide would echo these deficiencies. One survey of 450 asthma patients in Saudi Arabia suggested that just over $40 \%$ had never had any formal education on how to use inhalers (18), while $57 \%$ of COPD patients hospitalized for exacerbations in British Columbia reported having no inhaler education in the six months before their hospitalization (5). Even when inhaler education is implemented, the results are inconsistent. A survey of physicians in Quebec found that, on average, they taught only $30 \%$ of their COPD patients how to use their inhalers (19). Only 28\% of over 1500 Spanish physicians surveyed reported checking their patients' technique when prescribing a new inhaler (12).

While physicians may find that time constraints and a lack of appropriate placebo devices available for demonstration purposes effectively limit their abilities to impart proper inhaler technique (20), inadequacies in their own knowledge regarding these devices must also be considered a critical barrier. Before enrollment, very few physicians participating in our education program felt confident in their abilities to impart inhaler technique to their patients. Indeed, the results of formal testing of physicians on inhaler proficiency are often disappointing. The same survey of Spanish physicians revealed that only $14 \%$ had accurately identified the key steps to using MDIs and DPIs (one-quarter of physicians, for example, erroneously believed that DPIs required slow inspiratory flow rates) (12). Similarly, in a study testing MDI technique in pediatric residents, most were unable to correctly demonstrate the proper inspiratory and breath-holding maneuvers critical for successful use (21). Evaluations of pharmacists (22-24) 
and nurses (25) appear suggest that these health care providers are no better in providing the correct teaching.

Given the current state of health care provider comfort on devices, it is perhaps not surprising that studies repeatedly show high error rates among patients using inhalers for COPD and asthma $(6,26)$. Errors made by asthma patients when using the Diskus ${ }^{\circledR}$ and Turbuhaler ${ }^{\circledR}$ were found to mirror those made by the pharmacists training them, with particularly poor adherence with the exhalation and breathholding steps in both groups (23). Needless to say, before significant improvement can be made in patients, first ensuring competence among providers is a necessary task. Once instructed, nearly all FPs enrolled in our program felt confident in their teaching abilities, rating the quality of their inhaler teaching as good to excellent, which was markedly improved from before. Although not formally assessed in the present study, the benefits of enhanced inhaler education have been demonstrated in multiple randomized controlled trials. Asthma patients assigned to formal inhaler education arms achieve greater improvements in asthma control scores (27), while COPD patients undergoing intensive training have fewer exacerbations, emergency room visits and hospitalizations compared with those without similar instruction $(9,28)$.

There are several limitations to our study. First, as is common with most survey-based applications, we were only able to capture a portion of our target population. As a result, selection bias is a possibility and could influence the results of our study. Secondly, patient outcomes were not formally assessed so the impact of physician education on metrics of asthma and COPD control remains unclear. Finally, we acknowledge that primary care physicians are merely one aspect of an integrated health care system. Inhaler education provided by pharmacists and nurses, for example, plays an equally important role in respiratory health, but was beyond the purview of our study. Expansion of our education program to these allied health care professionals could further improve access to inhaler teaching, allowing it to occur in a multitude of health care settings.

In summary, we propose herein an education program directed at health care providers to improve the quality of inhaler device teaching in outpatient clinical practices. Aimed at addressing the many deficiencies in inhaler device proficiency within providers themselves, this program was able to improve physician confidence and comfort with inhaler devices, thus allowing more to institute inhaler education in their own practices. Proper use of inhaler medications is a cornerstone of COPD and asthma treatment and improved efforts at educating patients must be considered a priority for all health care providers.

FUNDING: Financial support for this educational program was provided by AstraZeneca Canada Inc.

DISCLOSURES: The authors have no finacial disclosures or conflicts of interest to declare.

\section{APPENDIX 1}

\section{ASTHMA AND COPD INHALER DEVICE PROGRAM}

\section{Baseline Questionnaire:}

Name (optional)

Years in practice:

$$
\square \text { 1-5 } \square \text { 5-10 } \square \text { 10-15 } \square>15
$$

Appropriate number of asthma and/or COPD patients seen per week:

$$
\square 1-10 \quad \square 10-20 \quad \square>20
$$

Have you received hands on education on inhaler device use?

$$
\square \text { Yes } \quad \square \text { No }
$$

When and how was this taught (i.e. med school, CHE, one on one from an educator)?

Do YOU educate or check your own patient's ability or technique on how to use their inhaler device appropriately and effectively?
$\square$ No
Who does teach them?

Yes, I do my own teaching. I teach appropriate us of the:

$\square$ Pressurized aerosol inhaler (pMDI)

$\square$ Dry powder inhalers (Diskus, Twisthaler, Turbuhaler)

$\square$ Space device

Does your education include how to tell if the device is empty and how to care for the device (cleaning, storing, etc...)?

$\square$ Yes $\quad \square$ No

If you do not educate patients on respiratory devices please indicate why (more than one answer is acceptable):

$\square$ Too busy to teach

$\square$ Pharmacist will take care of this

$\square$ Patients are typically good at using devices

$\square$ Other:

Please indicate if you agree/disagree with the following statements:

MDI's (+/- spacer) are better than powder devices in patients with low inspiratory flow (ex. Elderly COPD patients)

\section{$\square$ Agree $\square$ Disagree}

With either a nebulizer, you know you're getting the appropriate dose of medication every time.

\section{$\square$ Agree $\square$ Disagree}

Most patients know how to use their device as they have been using it for years - usually it's only the newly diagnosed patients that need some coaching.

$$
\square \text { Agree } \square \text { Disagree }
$$

Please indicate what you feel your level of competency is in educating your patients on how to use and care for their inhaler device

$\square$ Fully competent

$\square$ Somewhat competent

$\square$ Not competent

Other comments:

\section{APPENDIX 2}

\section{POST PROGRAM DEVICE EDUCATION SURVEY}

Insert baseline questions: Program attended, number of patients seen in a week, years of practice

Pre-program (circle your answer)

Poor Fair Adequate Good Excellent

Post-program (circle your answer)

Poor Fair Adequate Good Excellent

Prior to attending this program, I did the following for respiratory device education:

$\square$ I assumed patients were being trained by Allied Health Care Providers (ex. Pharmacist, RN, Nurse Practitioners, Certified Educators) and so I rarely educated on proper device technique

$\square$ I did the majority of the respiratory device education for my patients

Other

After attending this program, I have instituted device education in the following manner:

$\square$ I now do the majority of the respiratory device education for my patients

$\square$ Although I do not do the majority of device education, I have trained my support staff and AHCP's to ensure it is done properly and on a consistent basis for most of my patients

$\square$ I see the need for device education, however, I simply don't have enough, and so far, for most patients, I still assume Allied Health Care Providers in my community (ex. Pharmacist, RN, Nurse Practitioners, Certified Educators) will educate my patients on proper device technique 
Other

When I ask the patient, "Show me how you use your device", it usually takes minutes to review their technique and make effective adjustments:

$\square 1$ minute $\square 2$ minutes $\square 3-5$ minutes $\square 10$ minutes

$\square$ Other (enter the exact number of minutes it takes you in the comment box)

Which view point best describes yours:

$\square$ Device education should be given regardless of why a patient is seeing me - upon every visit

$\square$ Device education should only be given to new and existing respiratory disease patients on device technique who are seeing me for their respiratory condition

$\square$ Device education should only be given to patients with new prescriptions

Please list ideas/actions you have taken to ensure this education does not take up too much consult time

List how you have changed your practice with respect to device education not mentioned above

Is there anything that you felt could have been added to the program?

List the most eye opening gem(s) you took away from this program:

\section{REFERENCES}

1. Statistics Canada. 2014. Health Trends. Statistics Canada Catalogue No. 82-213-XWE. Ottawa. Released June 12, 2014. <www12.statcan.gc.ca/health-sante/82-213/index.cfm?Lang=ENG> (Accessed December 18, 2014).

2. Gershon AS, Guan J, Victor JC, Goldstein R, To T. Quantifying health services use for chronic obstructive pulmonary disease. Am J Respir Crit Care Med 2013;187:596-601.

3. Ismaila AS, Sayani AP, Marin M, Su Z. Clinical, economic, and humanistic burden of asthma in Canada: a systematic review. BMC Pulm Med 2013;13:70.

4. Bryant L, Bang C, Chew C, Baik SH, Wiseman D. Adequacy of inhaler technique used by people with asthma or chronic obstructive pulmonary disease. J Prim Health Care 2013;5:191-8.

5. Batterink J, Dahri K, Aulakh A, Rempel C. Evaluation of the use of inhaled medications by hospital inpatients with chronic obstructive pulmonary disease. Can J Hosp Pharm 2012;65:111-8.

6. Wieshammer S, Dreyhaupt J. Dry powder inhalers: Which factors determine the frequency of handling errors? Respiration 2008;75:18-25.

7. Melani AS, Bonavia M, Cilenti V, et al. Inhaler mishandling remains common in real life and is associated with reduced disease control. Respir Med 2011;105:930-8.

8. Basheti IA, Reddel HK, Armour CL, Bosnic-Anticevich SZ. Improved asthma outcomes with a simple inhaler technique intervention by community pharmacists. J Allergy Clin Immunol 2007;119:1537-8.

9. Tommelein E, Mehuys E, Van Hees T, et al. Effectiveness of pharmaceutical care for patients with chronic obstructive pulmonary disease (PHARMACOP): A randomized controlled trial. Br J Clin Pharmacol 2014;77:756-66.
10. Yildiz F. Importance of inhaler device use status in the control of asthma in adults: The asthma inhaler treatment study. Respir Care 2014;59:223-30.

11. Rene-Henri N, Khamla Y, Nadaira N, et al. Community pharmacists' interventions in asthma care: A descriptive study. Ann Pharmacother 2009;43:104-11.

12. Plaza V, Sanchis J, Roura P, et al. Physicians' knowledge of inhaler devices and inhalation techniques remains poor in Spain. J Aerosol Med Pulm Drug Deliv 2012;25:16-22.

13. Basheti IA, Qunaibi EA, Hamadi SA, Reddel HK. Inhaler technique training and health-care professionals: Effective longterm solution for a current problem. Respir Care 2014;59:1716-25.

14. Davis D, Galbraith R. Continuing medical education effect on practice performance: Effectiveness of continuing medical education: American College of Chest Physicians Evidence-Based Educational Guidelines. Chest 2009;135:42s-48s.

15. Sestini P, Cappiello V, Aliani M, et al. Prescription bias and factors associated with improper use of inhalers. J Aerosol Med 2006;19:127-36.

16. Melani AS, Zanchetta D, Barbato N, et al. Inhalation technique and variables associated with misuse of conventional metered-dose inhalers and newer dry powder inhalers in experienced adults. Allergy Asthma Clin Immunol 2004;93:439-46.

17. Ronmark E, Jögi R, Lindqvist A, et al. Correct use of three powder inhalers: Comparison between Diskus, Turbuhaler, and Easyhaler. J Asthma 2005;42:173-8.

18. Al-Jahdali H, Ahmed A, Al-Harbi A, et al. Improper inhaler technique is associated with poor asthma control and frequent emergency department visits. Allergy Asthma Clin Immunol 2013;9:8

19. Boulet LP, Devlin H, O'Donnell DE. The Physicians' Practice Assessment Questionnaire on asthma and COPD. Respir Med 2011;105:8-14.

20. Reznik M, Jaramillo Y, Wylie-Rosett J. Demonstrating and assessing metered-dose inhaler-spacer technique: Pediatric care providers' self-reported practices and perceived barriers. Clin Pediatr 2014;53:270-6.

21. Amirav I, Goren A, Pawlowski NA. What do pediatricians in training know about the correct use of inhalers and spacer devices? J Allergy Clin Immunol 1994;94:669-75.

22. Ali HD, Worku GS, Alemayehu AA, Gebrehiwot WH. Competence in metered dose inhaler technique among dispensers in Mekelle. Allergy Asthma Clin Immunol 2014;10:18.

23. Basheti IA, Qunaibi E, Bosnic-Anticevich SZ, et al. User error with Diskus and Turbuhaler by asthma patients and pharmacists in Jordan and Australia. Respir Care 2011;56:1916-23.

24. Gemicioglu B, Borekci S, Can G. Investigation of knowledge of asthma and inhaler devices in pharmacy workers. J Asthma 2014;51:982-8.

25. De Tratto K, Gomez C, Ryan CJ, Bracken N, Steffen A, Corbridge SJ. Nurses' knowledge of inhaler technique in the inpatient hospital setting. Clin Nurse Spec 2014;28:156-60.

26. Ganguly A, Das AK, Roy A, Adhikari A, Banerjee J, Sen S. Study of proper use of inhalational devices by bronchial asthma or COPD patients attending a tertiary care hospital. J Clin Diagn Res 2014;8:Hc04-07.

27. Garcia-Cardenas V, Sabater-Hernandez D, Kenny P, Martinez-Martinez F, Faus MJ, Benrimoj SI. Effect of a pharmacist intervention on asthma control. A cluster randomised trial. Respir Med 2013;107:1346-55.

28. Goris S, Tasci S, Elmali F. The effects of training on inhaler technique and quality of life in patients with COPD. J Aerosol Med Pulm Drug Deliv 2013;26:336-44. 


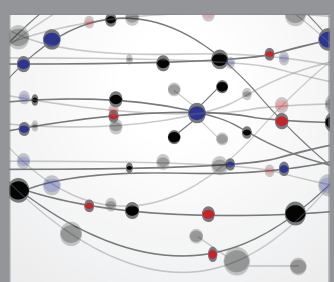

The Scientific World Journal
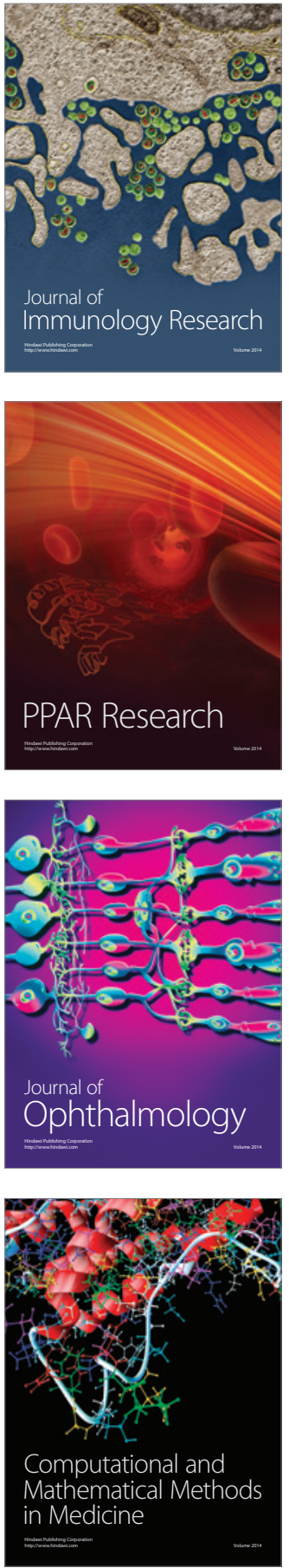

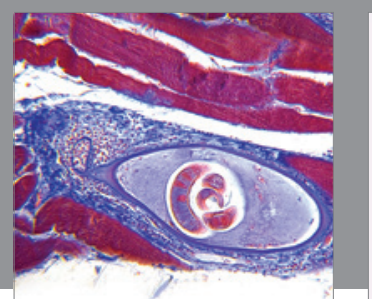

Gastroenterology Research and Practice

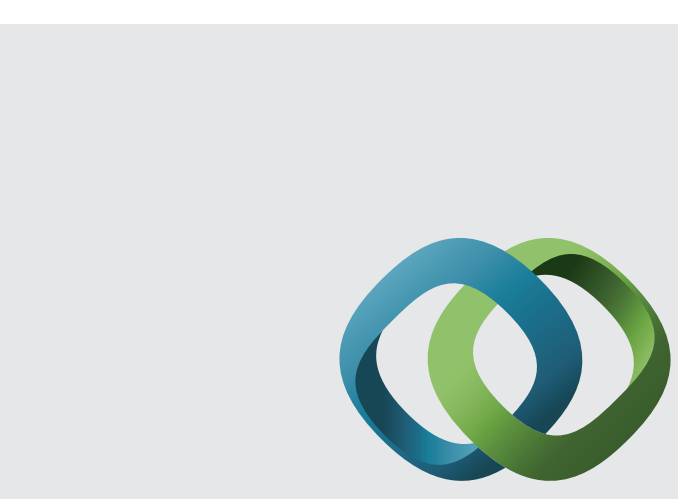

\section{Hindawi}

Submit your manuscripts at

http://www.hindawi.com
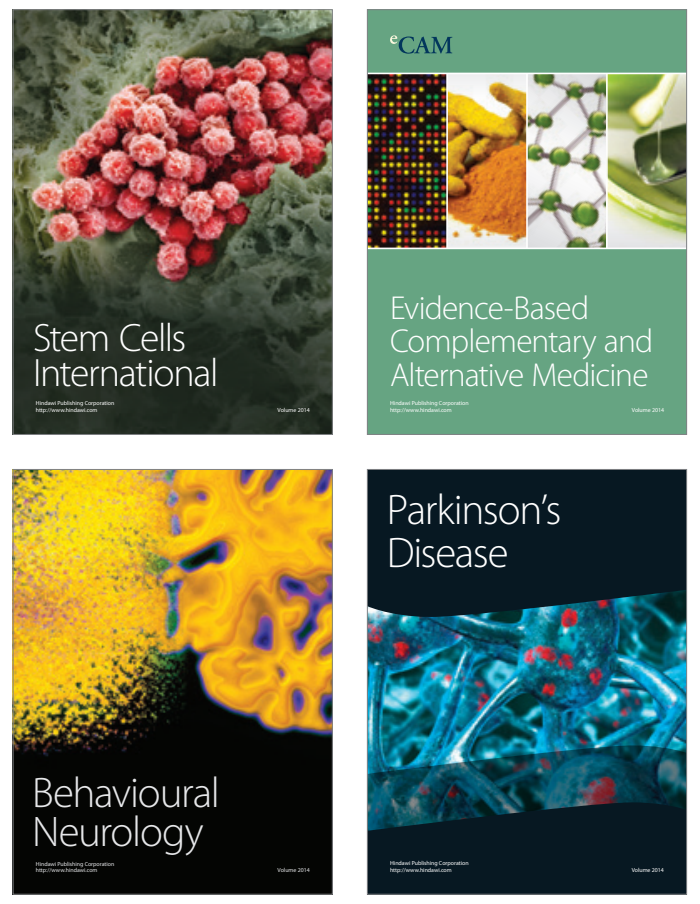
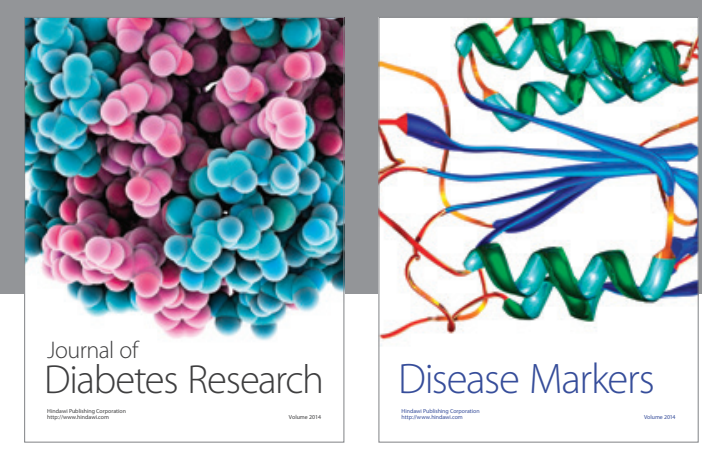

Disease Markers
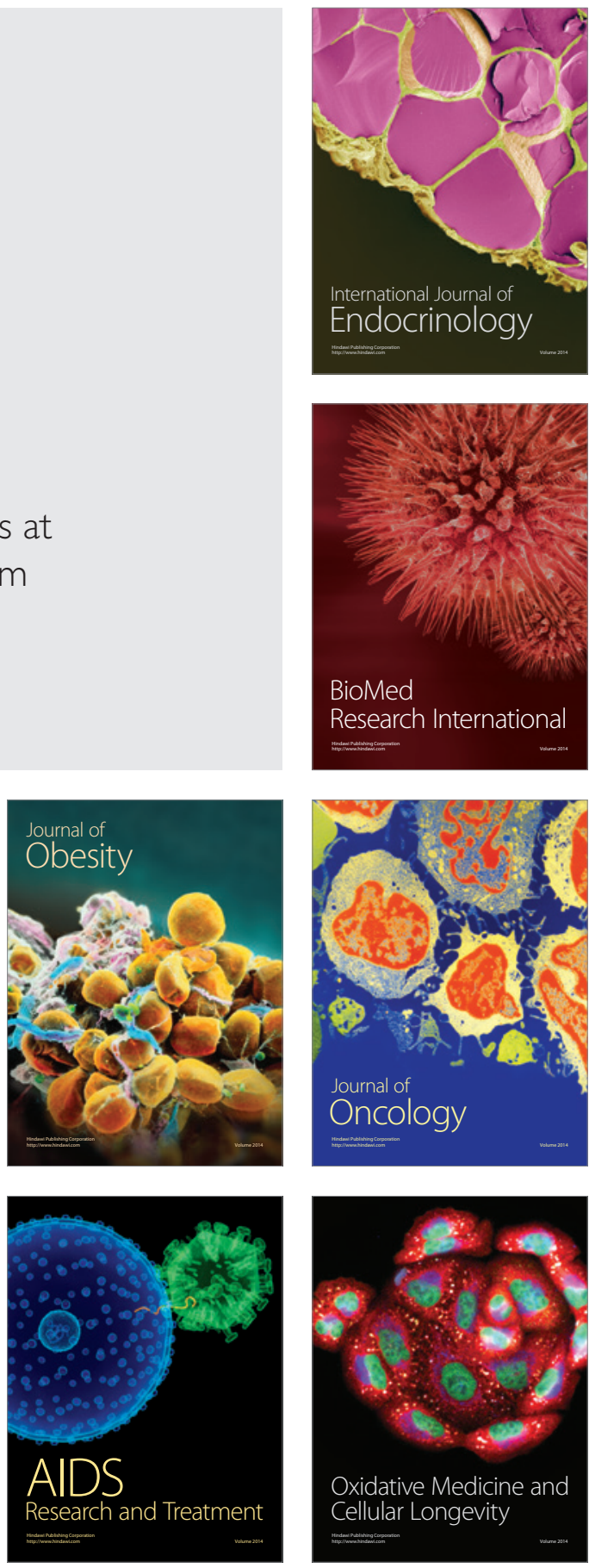